\title{
EFFECTIVENESS OF OPEN DISCECTOMY FOR IVDP - A PROSPECTIVE STUDY
}

\author{
Ranganath H. D ${ }^{1}$, J. N. Sridhara Murthy2, M. Prabu
}

\section{HOW TO CITE THIS ARTICLE:}

Ranganath H. D, J. N. Sridhara Murthy, M. Prabu. "Effectiveness of Open Discectomy for IVDP - A Prospective Study". Journal of Evolution of Medical and Dental Sciences 2014; Vol. 3, Issue 06, February 10;

Page: 1346-1353, DOI:10.14260/jemds/2014/1990

ABSTRACT: BACKGROUND AND OBJECTIVES: Low back pain (LBP) results in loss in productivity than any other medical condition. Approximately 70-80\% of all people will develop LBP in their life. There are various causes of LBP, out of which the lumber disc herniation is one of the most frequent reason for physical, functional restriction in patients. Patients who have undergone surgical treatment are found to possess increased short term outcome instead of conservative treated patients. Surgically treated patients experienced fast pain relief, improvement of function \& satisfaction in comparison to conservative patients. The comparative results of patients treated with surgery and conservatively treated patients have revealed that surgical treatment is much better at short term follow up (upto 1 year) however no variations have been shown among treatment at long term follow up. Some patients operated for spine diseases are still left with poor results. The present study aims to evaluate the efficiency of open discectomy for $\mathrm{L}_{4}-\mathrm{L}_{5}$ IVDP prospectively. METHODS: 30 cases of lumbar disc prolapse, above 18 years of age admitted at KIMS hospital, Bangalore with MRI showing conclusive disc prolapsed were taken for the study. They were pre operatively evaluated for their ODI score. Only those patients who have scored $40 \%$ and above in ODI were included in the study. They underwent discectomy. Methods of surgery used were fenestration, extended fenestration, hemilaminectomy \& total laminectomy as per operative requirement. Followups were carried out at 6,12 and 24weeks on selected areas. Pre and post of ODI total and sub scale scores were compared at the end of 24 weeks. RESULTS: There was a significant reduction of post operative ODI score indicating good success rate in open disectomy. The pre operative mean ODI score was 58.28, SD was 5.06 and the post operative mean ODI score was 15.28 and SD was 2.40 with $t$ value of 38.56 and $p$ value of 0.000 which was significant at $p<0.001$ level. The ten sub scales of ODI also showed significant reduction of post operative ODI scores indicating open disectomy resulted in significant improvement in the functional outcome. INTERPRETATION AND CONCLUSION: The procedure of discectomy (fenestration) for LIVDP in relieving symptoms and restoring the function of patients is excellent.

KEYWORDS: Low Back Ache (LBA), Oswestry Disability Index (ODI), Inter vertebral Disc Prolapse (IVDP), Magnetic Resonance \& Imaging (MRI)

INTRODUCTION: In industrialized countries, approximately $50-80 \%$ of the adult population has low back pain at sometimes in their lives. There are various causes for low back pain like injury to the supporting paraspinal muscles, ligaments, facet joint cartilage, vertebral bones and compression of neuronal structures due to herniated nucleus pulposus of lumbar disc ${ }^{1}$, out of which the lumbar disc herniation is one of the most frequent reason for physical, functional restriction in patients ${ }^{2}$. Impairments of the back and spine are ranked as the most frequent cause of limitation of activity in 
people younger than 45 years as mentioned by the National centre for Health Statistics ${ }^{3}$. Patients with symptoms that persist beyond six weeks and when there is a demonstratable MRI disc pathology are candidates for surgical removal. ${ }^{4}$ The Oswestry Disability Index ${ }^{5}$ helps to find out disease specific disability and studies support that ODI score was the better determinant of post operative functional outcome. ${ }^{6}$

METHODOLOGY: The present study includes 30 cases of lumbar disc prolapse treated during the period of May 2011 to September 2013 in KIMS hospital, Bangalore. The patients underwent radiological investigations (MRI) to confirm the diagnosis and to know the level of lesions.

The study was carried out on the patients with ODI score more than $40 \%$ (severe disability) and having the age of above 18 years and admitted in the orthopedic wards. All patients were treated surgically by open discectomy.

\section{Inclusion Criteria:}

- Un-relieved pain radiating along the course of the nerve in the lower-limb respectively,

- Nerve tension signs-positive

- Associated neurological deficits.

\section{Exclusion criteria:}

Age less than 18 yrs.

1. Thoraco - lumbar injuries.

2. Lumbar - canal stenosis.

3. Spondylolisthesis.

4. Fail back syndrome.

5. Medically unfit for surgery.

6. Peripheral neuropathy.

7. Infective conditions.

8. Tumors (neoplastic) lesion.

Collection of data: After the detailed history and clinical examination, based on selection criteria, on 30 patients, ODI was administered and the MRI was screened for conclusive disc prolapse.

Sample procedure: prospective study: Patients with signs and symptoms of disc prolapse, ODI $>40 \%$, MRI showing conclusive disc prolapse and who come under the inclusion criteria were selected and admitted.

1. Investigations required for surgery was done.

2. A pre anaesthetic evaluation was carried out.

3. Pre operative preparations were made and informed written consent was taken.

4. Methods such as fenestration, extended fenestration, hemi laminectomy, total laminectomy was chosen according to the per-operative requirement for discectomy.

5. Follow ups $-6,12$ and 24 weeks. 
RESULTS: The descriptive statistics of frequency and percentage were used for analyzing the sociodemographic data such as gender, age, occupation, symptoms, nerve tension signs, surgical approaches, complications, etc. The inferential statistics ' $t$ ' test was used to compare pre and post operative total ODI score and also the 10 sub scale scores of ODI.

\begin{tabular}{|c|c|c|c|c|c|c|c|}
\hline \multirow{2}{*}{ S. No } & Gender & $\begin{array}{c}\text { Above 18 years } \\
\text { \& upto 30 years }\end{array}$ & $\begin{array}{c}31-40 \\
\text { Years }\end{array}$ & $\begin{array}{c}41-50 \\
\text { Years }\end{array}$ & $\begin{array}{c}\text { Above } \\
50 \text { years }\end{array}$ & Total & percentage \\
\hline 1 & Male & 03 & 09 & 04 & 05 & 21 & $70 \%$ \\
\hline 2 & Female & 01 & 04 & 00 & 04 & 09 & $30 \%$ \\
\hline \multicolumn{2}{|c|}{ Total } & $\mathbf{0 4}$ & $\mathbf{1 3}$ & $\mathbf{0 4}$ & $\mathbf{0 9}$ & $\mathbf{3 0}$ & \multirow{2}{*}{100.00} \\
\hline \multicolumn{2}{|c|}{ percentage } & 13.33 & 43.34 & 13.33 & 30.00 & 100.00 & \\
\hline
\end{tabular}

Table 1: Distribution of the study subjects based on the gender and age

$\mathrm{n}=\mathbf{3 0}$

Data compiled from the patients at KIMS, Bangalore

The above table no:01 indicated that 43.34 percent $(n=13)$ of the patients were between the age group of 31-40 years, 30 percent of the patients fall in the category of above 50 years. Another13.33 percent of the patients respectively belong to the age group of 18 to 30 years and 41 to 50 years.

The study revealed that majority of the patients (43.34\%) fall in the age group of 31 to 40 years. Mean age: 43.3 years.

\begin{tabular}{|c|l|c|c|}
\hline S.No & occupation & Number of Patients & Percentage of the patients \\
\hline 1 & Agriculture & 11 & 36.67 \\
\hline 2 & Housewife & 8 & 26.67 \\
\hline 3 & Coolie & 5 & 16.67 \\
\hline 4 & Clerk & 1 & 03.33 \\
\hline 5 & Merchant & 3 & 10.00 \\
\hline 6 & Student & 1 & 03.33 \\
\hline 7 & Mechanic & 1 & 03.33 \\
\hline \multicolumn{2}{|c|}{ Total } & $\mathbf{3 0}$ & $\mathbf{1 0 0 . 0 0}$ \\
\hline
\end{tabular}

Table 2: Distribution of the study subjects based on the Occupation

$\mathbf{n}=\mathbf{3 0}$

Data compiled from the patients at KIMS, Bangalore

The above table no: 02 highlighted the occupation of the study subjects. Out of total number of the subjects 36.67 percent $(n=11)$ were Agriculturists, 26.6 percent $(n=8)$ were house wives, 16.67percent $(n=5)$ were coolies, 10 percent $(n=3)$ were Merchants, another 3.33 percent $(n=1)$ were respectively Clerks, Students, Mechanics.

The studies revealed that majority (36.67 percent) of the patients were agriculturists. 


\begin{tabular}{|c|l|c|c|}
\hline S.No & \multicolumn{1}{|c|}{ Symptoms } & Number of patients & $\mathbf{\%}$ \\
\hline 1 & Low Back ache & 30 & 100 \\
\hline 2 & Radicular pain & 30 & 100 \\
\hline 3 & Paraesthesias & 07 & 23.33 \\
\hline 4 & Weakness & 06 & 20.00 \\
\hline 5 & Sensory Loss & 12 & 40.00 \\
\hline 6 & B/B Involvement & 0 & 0 \\
\hline
\end{tabular}

Table 3: Distribution of the study subjects based on the Symptoms

$\mathbf{n}=\mathbf{3 0}$

Data compiled from the patients at KIMS, Bangalore

The above table no:03 indicates that majority 100\%(n=30) had lower backache and radicular pain among them $23.3 \%(n=7)$ had paraesthesia, $20 \%(n=6)$ had weakness, $40 \%(n=12)$ had sensory loss and none had bladder bowel involvement.

The study revealed that majority $100 \%(n=30)$ had low backache and radicular pain.

\begin{tabular}{|c|c|c|c|}
\hline S.No & Nerve tension signs & $\begin{array}{c}\text { Number of patients } \\
(\mathbf{n = 3 0 )}\end{array}$ & $\mathbf{\%}$ \\
\hline 1 & SLRT & 27 & 90 \\
\hline 2 & Lasegues test & 25 & 83.3 \\
\hline \multicolumn{2}{|c|}{ Table 4: Distribution of the study subjects based on Nerve Tension Signs } \\
\hline
\end{tabular}

Data compiled from the patients at KIMS, Bangalore

The above table no: 04 revealed that 90 percent $(n=27)$ of the patients had positive SLRT. Another 83.3 percent $(n=25)$ of the patients had positive lasegues test.

The study revealed that majority (90 percent) of the patients had positive SLRT.

\begin{tabular}{|c|c|c|c|}
\hline S.NO & QUADRENTS OF IVDP & NUMBER & $\mathbf{\%}$ \\
\hline 1 & Central & 1 & 3.4 \\
\hline 2 & Para central & 24 & 80 \\
\hline 3 & Foraminal & 3 & 10 \\
\hline 4 & Far lateral & 2 & 6.6 \\
\hline
\end{tabular}

Table 5: Distribution of the study subjects based on the quadrants of IVDP 
The above table No:05 depicts that majority $80 \%(n=24)$ had a presentation of para central type and others had $10 \%(n=3)$ foraminal type, $6.6 \%(n=2)$ far lateral and $3.4 \%(n=1)$ central. The study revealed that majority $80 \%(n=24)$ had a presentation of para central type.

\begin{tabular}{|c|l|c|c|}
\hline S. No & \multicolumn{1}{|c|}{ Approaches } & Patients & $\mathbf{\%}$ \\
\hline 1 & Fenestration & 21 & 70 \\
\hline 2 & Extended fenestration & 6 & 20 \\
\hline 3 & Partial laminectomy & 1 & 3.4 \\
\hline 4 & Hemi laminectomy & 2 & 6.6 \\
\hline
\end{tabular}

Table 6: Distribution of the study subjects based on the approach.

The above table No: 06 reveals that majority 70\% $(n=21)$ of the patients underwent fenestration, $20 \%(n=6)$ patients underwent extended fenestration, 6.6\% (n-2) of patients underwent hemi laminectomy and 3.4\% $(n=3.4)$ of patients underwent partial laminectomy. The study revealed that majority $70 \%(n=21)$ of the patients underwent fenestration.

\begin{tabular}{|c|c|c|c|}
\hline S.No & \multicolumn{1}{|c|}{ Complications } & Number of patients & $\mathbf{\%}$ \\
\hline 1 & Absent & 28 & 93.3 \\
\hline 2 & Present \& Dural Puncture (DP) & 2 & 6.7 \\
\hline \multicolumn{2}{|r|}{ Total } & 30 & 100 \\
\hline
\end{tabular}

\section{Table 7: Distribution of the study subjects based on the Complications}

$(n=30)$

Data compiled from the patients at KIMS, Bangalore

The above said table no: 07 depict that 93.3 percent $(n=28)$ of the patients did not had the post operative complications after the surgery. Only 6.7 percent $(n=2)$ of the patients had the postoperative complication as a Dural Puncture.

The study revealed that majority (93.3 Percent) of the patients did not develop any complication after the surgery.

\begin{tabular}{|c|l|c|c|}
\hline S. No & Results & $\begin{array}{c}\text { Number of patients } \\
(\mathbf{n = 3 0})\end{array}$ & $\mathbf{\%}$ \\
\hline 1 & Fair & 02 & 06.67 \\
\hline 2 & Good & 07 & 23.33 \\
\hline 3 & Excellent & 21 & 70.00 \\
\hline \multicolumn{2}{|c|}{ Total } & $\mathbf{3 0}$ & $\mathbf{1 0 0 . 0 0}$ \\
\hline
\end{tabular}

Table 8: Distribution of Results of the Surgical Treatment

The table no: 08 explains that 70 percent $(n=21)$ of the study subjects showed excellent improvement after the surgical treatment, another 23.33 percent $(n=7)$ of them showed good 
improvement and only 6.7 percent $(n=2)$ of them showed poor improvement after the surgical treatment.

The study revealed that majority 70percent of the patients showed excellent result after the surgical treatment.

\begin{tabular}{|c|c|c|c|c|c|c|c|}
\hline \multirow{2}{*}{\begin{tabular}{c}
\multirow{2}{*}{$\begin{array}{c}\text { ODI } \\
\text { Score }\end{array}$} \\
\multirow{2}{*}{ N }
\end{tabular}} & \multicolumn{2}{|c|}{ Pre -0p } & \multicolumn{2}{c|}{ Post -0p } & \multicolumn{2}{c|}{} \\
\cline { 2 - 8 } & & Mean & SD & Mean & SD & t & P Value \\
\cline { 2 - 8 } & 30 & 58.28 & 5.06 & 15.38 & 2.40 & 38.56 & $.000^{*}$ \\
\hline
\end{tabular}

Table 9: Comparison of pre -operative and post-operative ODI score

*Significant at $\mathbf{p}<0.001$

\begin{tabular}{|l|c|c|c|c|c|c|c|}
\hline \multirow{2}{*}{\multicolumn{1}{|c|}{ Section }} & \multicolumn{3}{|c|}{ Pre -Op } & \multicolumn{4}{c|}{ Post -0p } \\
\cline { 2 - 8 } & n & Mean & SD & Mean & SD & t & P Value \\
\hline Pain intensity & 30 & 3.00 & .27 & .79 & .41 & 28.828 & $.000^{*}$ \\
\hline Personal care & 30 & 3.13 & .35 & .93 & .69 & 15.832 & $.000^{*}$ \\
\hline Lifting & 30 & 3.1 & .48 & .60 & .62 & 16.699 & $.000^{*}$ \\
\hline Walking & 30 & 3.03 & .62 & .70 & .60 & 13.857 & $.000^{*}$ \\
\hline Sitting & 30 & 3.47 & .82 & .66 & .71 & 12.930 & $.000^{*}$ \\
\hline Standing & 30 & 1.80 & 1.16 & .56 & .63 & 5.401 & $.000^{*}$ \\
\hline Sleeping & 30 & 2.97 & .72 & .86 & .73 & 11.562 & $.000^{*}$ \\
\hline Sex life & 30 & 2.53 & 1.04 & .80 & .76 & 8.308 & $.000^{*}$ \\
\hline Social Life & 30 & 3.23 & .77 & .96 & .72 & 13.145 & $.000^{*}$ \\
\hline Traveling & 30 & 2.96 & .81 & .86 & .63 & 13.001 & $.000^{*}$ \\
\hline
\end{tabular}

Table 10: Comparison of pre -operative and post operative ODI Sub scale score

\section{*Significant at $\mathbf{p}<0.001$}

The table no: 09 and Table No. 10 show that total and subscales mean scores obtained on ODI scale among the study subjects. The pre operative total mean score was $58.28 \pm 5.06$ and post operative total mean score was $15.38 \pm 2.40$. The comparison of the pre and post-operative total mean score was done with paired t test (38.56). The P Value showed P- $<0.001$. Similar findings were seen in all the 10 sub scales where post operative mean scores were lesser than the pre-operative ODI scores The $\mathrm{p}$ value suggest that there is a significant improvement of functional outcome between pre operative and post operative level of function.

DISCUSSION: Lumbar disc prolapse is an important cause for backache. It is the most prominent problem in the $3^{\text {rd }}$ and $4^{\text {th }}$ decades of life. IVDP at Lumbar region is a major contributor of functional disability. Open disectomy (Fenestration) is found to be the most appropriate operative intervention in patients with lumbar intervertebral disc prolapse. Hence, in the present study an attempt is made to evaluate the effectiveness of the open discectomy by comparing the pre- 
operative ODI score with post-operative ODI score as well as finding out the complications following the open disectomy for IVDP.

Patients with IVDP who have para central type herniation are treated well with open disectomy using Fenestration. It is the surgical approach performed on the majority of the patients $(70 \%)$ in the present study (Table 6). Complications after open discectomy in the present study was dural tear (6.6\%) (Table 7) correlates well with the study by Richard Davis ${ }^{7}$ (4.2\%) and study by Sangwan et al ${ }^{7}(3.9 \%)$. Open disc excision under direct vision offers sufficient adequate exposure for lumbar disc excision with smaller incision, lesser morbidity, shorter convalescence and hence, the lesser complications rates.

The treatment outcome of the present study Table 8 shows $70 \%$ of the patients, excellent result in, after the open discectomy. This finding correlates well with the figures of studies by Pappes et $\mathrm{al}^{8}(77.6 \%)$ and with that of studies by Richard Davis (89\%) ${ }^{9}$

The functional outcome after open discectomy by fenestration is compared between Pre operative ODI score, (Mean 58.28 with standard deviation of 5.06) and post operative ODI score (Mean 15.38 with standard deviation of 2.40), there was a significant reduction in the ODI score (Table 9), and also in all 10 sub-scales (Table 10). This finding correlates well with the study of Chen et $\mathrm{al}^{10}$, where pre operative ODI mean score was 57.43 and it came down to Post operative mean score of 11.52 showing excellent improvement in the function outcome.

CONCLUSION: The results demonstrated that, the procedure of open discectomy (fenestration) for lumbar intervertebral disc prolapse in relieving symptoms and restoring the function of patients is excellent.

- Open discectomy by fenestration is an easy procedure, economical, with least complication and the most effective means of treating lumbar disc prolapse.

- Standard open discectomy is still the "gold standard" in operative treatment of lumbar disc prolapse.

\section{BIBLIOGRAPHY:}

1. Bruce Carl Anderson. Lumbosacral Spine, Chapter-9. Office Orthopaedic for Primary Care: Diagnosis. Elsevier Health Science, 3rd edition- 2005:150.

2. Figen Yilmaz, Adem Yilmaz, Funda Merdol, Demet Parlar, Fusun Sahin and Banu Kuran. Efficacy of Dynamic Lumbar Stabilization Exercise in Lumbar Microdiscectomy. Journal of Rehabilitation Medicine 2003; 35:163-7.

3. Wood, George W. Lower back pain and disorders of intervertebral disc. Chapter 39, Campbell's Operative orthopaedics, Vol. II. 10 ${ }^{\text {th }}$ Edn, Edt, Canale S. Terry, Missouri, Mosby, 2003:1955-2029.

4. Andrew J. Schoenfeld and Bradley K Weiner. Treatment of lumbar disc herniation: Evidencebased practice. Available from: http://www.nchi.nlm.nih.gov/pmc/articles/PMC2915533.

5. Fairbank JC, Couper J, Davies JB, O'Brien JP. The Oswestry low back pain disability questionnaire. Physiotherapy. 1980; 66(8): 271- 3.

6. Puolakka, K, Ylinen J, Neva M.H, Kautiainen H, Hakkinen A. Risk factors for back pain-related loss of working time after surgery for lumbar disc herniation: a 5-year follow-up study. European Spine Journal. 2008; 17(3):386-92. 


\section{ORIGINAL ARTICLE}

7. Sangwan SS, Kundu ZS, Raj Singh, Kamboj P, Siwach RC, Aggarwal. Lumbar disc excision through fenestration. Indian Journal of Orthopaedics. 2006; 40:86-89.

8. Pappes CT. Harrington T, Sonntag VK. Outcome analysis in 645 surgically treated lumber disc herniation, Neurosurgery 1993; 32(5): 879.

9. Davis RA. A long term outcome analysis of 984 surgically treated herniated lumbar discs. Journal of Neurosurgery 1994; 80(3):415-21

10. Chen HT, Tsai CH, Chao SC, Kao TH, Chen YJ, Hsu HC, Shen CC, Tsou HK. Endoscopic discectomy of L5-S1 disc herniation via an interlaminar approach: Prospective controlled study under local and general anaesthesia. Surgical Neurology International, 2011:2:93.

\section{AUTHORS:}

1. Ranganath H. D.

2. J. N. Sridhara Murthy

3. M. Prabu

\section{PARTICULARS OF CONTRIBUTORS:}

1. Associate Professor, Department of Orthopaedics, Kempegowda Institute of Medical Sciences.

2. Professor and HOD, Department of Orthopaedics, Kempegowda Institute of Medical Sciences.

3. Final Year M.S. (Ortho) Student, Department of Orthopaedics, Kempegowda Institute of Medical Sciences.

\section{NAME ADDRESS EMAIL ID OF THE CORRESPONDING AUTHOR:}

Dr. Ranganath H.D,

\#1072, $11^{\text {th }}$ Main, $2^{\text {nd }}$ Stage, WOC Road, Mahalakshmipuram, Bangalore - 86.

Email- ranganath.kims@gmail.com

Date of Submission: 07/12/2013.

Date of Peer Review: 08/12/2013.

Date of Acceptance: 18/12/2013.

Date of Publishing: 04/02/2014 